\title{
Estacionamento Rotativo: Um Modelo Heurístico Baseado em Localização-Designação ${ }^{1}$
}

\author{
Liliane S. de Antiqueira* \\ Universidade Federal do Rio Grande, FURG \\ 96201-900, Rio Grande, RS \\ E-mail: lilianeantiqueira@ furg.br \\ Catia dos S. Machado \\ Universidade Federal do Rio Grande - Instituto de Matemática, Estatística e Física \\ 96201-900, Campus Carreiros, Rio Grande, RS \\ E-mail: catiadmt@terra.com.br \\ Elaine C. Pereira \\ Universidade Federal do Rio Grande - Instituto de Matemática, Estatística e Física \\ 96201-900, Campus Carreiros, Rio Grande, RS \\ E-mail: elainepereira@prolic.furg.br
}

\section{RESUMO}

No contexto atual do trânsito, o crescimento do número de automóveis e a falta de infraestrutura estão gerando sérios problemas de congestionamento nos centros das cidades. Tal situação gera um descompasso entre o aumento do número de carros e a falta de espaço nas grandes cidades, ocasionando um desequilíbrio entre a demanda e a oferta de vagas de estacionamento.

Com o intuito de solucionar este problema, diversas cidades implantaram o Estacionamento Rotativo Regulamentado (ERR) que, conforme [2] é uma medida de racionalização do uso da via, que coíbe os estacionamentos de longa duração e promove a constante troca dos veículos nas vagas. Em razão disso, propõe-se neste trabalho a aplicação de um modelo heurístico baseado em localização-designação para a melhoria do ERR na cidade de Rio Grande-RS. Tem como objetivo, apoiar os setores de fiscalização, através de uma ferramenta computacional que permita a elaboração de mapas e relatórios, possibilitando que fiscais tenham acesso a documentos atualizados das ruas a serem percorridas. Atualmente, estas informações são feitas de forma empírica e manual, como foi detectado na pesquisa realizada junto à empresa. A metodologia foi composta pela determinação do número $p$ de medianas, $\mathrm{p}=20$, que corresponde ao número de funcionários. Para isto, foi utilizada a heurística clássica Teitz e Bart [4], na qual considerou-se todos os trechos de quadra do grafo $G=(V, A)$ como potenciais medianas. A partir do conjunto $\mathrm{V}$ deve-se encontrar um conjunto $V_{20} \subset V$, tal que a soma das distâncias de cada trecho de quadra restante em $V^{\prime}=V-V_{20}$ até o trecho de quadra mais próximo em $V_{20}$ seja a mínima possível, ou seja, o conjunto com o menor número de transmissão, dado por:

$$
\sigma\left(V_{20}\right)=\sum_{v_{i_{L}}}^{L=106} w_{i} \times d\left(v_{i_{L}}, v_{i_{k}}\right) \text { para } \forall v_{i_{L}} \in V^{\prime} e v_{i_{k}} \in V_{20}
$$

Onde $\mathrm{V}$ é o conjunto dos trechos de quadra $V=\left\{v_{i}, \ldots, v_{126}\right\}$, sendo $i=1,2,3, \ldots, 126 ; V_{20}$ é o subconjunto de $\mathrm{V}$ pois $V_{20} \subset V$, ou seja, $V_{20}=\left\{v_{i_{1}} \ldots v_{i_{20}}\right\} ; V^{\prime}=V-V_{20}=\left\{v_{i_{1}} \ldots v_{i_{106}}\right\}$,

\footnotetext{
${ }^{1}$ Em [1] encontra-se um estudo inicial sobre a formação de setores e áreas do ERR, bem como a comparação dos algoritmos de Teitz \& Bart e Busca Tabu e a designação através do Problema de Transporte e Designação. No artigo Um modelo heurístico baseado em localização-designação aplicado ao ERR, o qual se encontra em fase de publicação na revista Journal of Transport Literature, fez-se um detalhamento da pesquisa, sendo que para a designação foi utilizado o método de Gillett e Johnson. Além disso, comparou-se os algoritmos Teitz \& Bart e Busca Tabu. Diferentemente do que é apresentado neste resumo, tem-se um recorte da dissertação Problema de Localização de Facilidades aplicado ao Estacionamento Rotativo, defendida em abril de 2013. O foco do ao resumo é mostrar a possibilidade de aplicação de um modelo heurístico para a formação de setores utilizando apenas o Algoritmo de Teitz \& Bart.
} 
sendo $i$ qualquer um dos 126 trechos de quadra de $V ; v_{i_{k}}$ são todos os vértices pertencentes ao subconjunto $V_{20}$, sendo $k=1, \ldots, 20 ; v_{i_{L}}$ são todos os trechos de quadra pertencentes ao conjunto $V^{\prime}$, sendo $L=1, \ldots, 106$ e $w_{i}$ é o peso associado em cada trecho de quadra, que para este problema será definido como 1 (um) pois todos os trechos de quadra poderão ser um vértice mediana. Após a determinação das medianas foi realizada a designação dos trechos de quadra às medianas mais próximas utilizando o Problema de Designação [3]. Considerou-se que existem 106 trechos de quadra com uma demanda $D_{i}$ a ser designada no trecho $i$, ou seja, $i=1,2, \ldots, 106$; 20 setores com uma capacidade $C_{j}$ disponível na mediana $j$, ou seja, $j=1,2, \ldots, 20 ; d_{i j}$ é o custo para designar um trecho de quadra $i$ ao setor $j$, ou seja, a distância percorrida pelos fiscais e $x_{i j}$ é o número de unidades a ser enviada da origem $i$ para o destino $j$. Logo $x_{i j}$ será 1 , se o trecho $i$ for designado para o setor $j$ e 0 caso contrário. Então:

$$
\text { Minimizar } Z=\sum_{j=1}^{20} \sum_{i=1}^{106} d_{i j} x_{i j}
$$

Sujeito a:

$$
\begin{aligned}
& \sum_{j=1}^{20} x_{i j}=1 \text { para } i=1,2, \ldots, 106 \\
& \sum_{i=1}^{106} x_{i j} D_{i} \leq C_{j} \text { para } j=1,2, \ldots, 20
\end{aligned}
$$

A função objetivo (2) designa os 106 trechos de quadra aos 20 setores de forma a minimizar a distância percorrida pelos fiscais dentre os trechos de cada setor. As restrições (3) é para que cada trecho $(i=1,2, \ldots, 106)$ seja designado a apenas um setor (não pode ter um trecho designado para dois setores, pois cada setor é composto por seus diferentes trechos), as restrições (4) mostram que cada setor $j$ possui capacidade $C_{j}$ que deve ser respeitada de acordo com a demanda $D_{i}$ do trecho $i$. E por último, as restrições (5) é para que todas as variáveis sejam binárias. Neste trabalho apresentou-se uma heurística de localização-designação para o problema do ERR. Na formação dos setores, o modelo matemático revelou-se de fácil implementação, rápido e bastante eficiente. Os resultados obtidos foram bastante satisfatórios, pois a partir de um mapa digitalizado da região e das coordenadas dos trechos de quadra, o aplicativo desenvolvido elabora todos os mapas de setores a serem fiscalizados, permitindo que qualquer alteração seja feita de forma automática sem causar maiores transtornos. Diante dos resultados obtidos com o estudo, conclui-se que o aplicativo desenvolvido possibilita a generalização do problema em estudo, servindo como modelo para outras regiões e municípios que necessitam de uma ferramenta computacional para a elaboração de mapas. Além disso, permite adicionar e remover trechos quando houver alterações no sistema, sendo possível mudar o mapa da região ou acrescentar bairros e ruas, conforme a necessidade.

\section{Palavras-chave:P-medianas, Designação, Estacionamento Rotativo}

\section{Referências}

[1] Antiqueira, L. S., Pereira, E. C. e Machado, C. S. (2012) Problema de Localização de Facilidades aplicado ao serviço de Estacionamento Rotativo. Anais do XXXII Encontro Nacional de Engenharia de Produção - ENEGEP, Bento Gonçalves.

[2] Elias, A. C. C, "Estacionamento Rotativo Pago em Via Pública", Dissertação de Mestrado, PPGEP- UFRGS, 2001.

[3] Marins, F. A. S, "Introdução à Pesquisa Operacional", São Paulo: cultura acadêmica: Universidade Estadual Paulista, 2011.

[4] Teitz, M. B.; Bart, P, "Heuristic Concentration: Two-stage Solution Construction", Operational Research Society, London, 1968. 